В данной работе рассмотрена законодательная база тьюторской поддержки детей с ограниченными возможностями здоровья и инвалидностью в условиях дошкольных учреждений: Федеральный государственный образовательный стандарт дошкольного образования, Единый квалификационный справочник должностей, Приказ Минздравсоцразвития РФ «Об утверждении профессиональных квалификационных групп должностей работников образования», Профессиональный стандарт тьютора. Выделены основы становления и развития тьюторского сопровождения в условиях инклюзивно ориентированных дошкольных образовательных организаций - формирование и развитие равного отношения ко всем обучающимся и создание специальных условий образовательной среды. Обозначены категории обучающихся, в отношении которых осуществляется тьюторская поддержка. Раскрыта технология проведения родительского собрания в период введения ребенка в инклюзивную группу. Определена специфика тьюторской деятельности в зависимости от этапа (адаптационный, контактный, самоопределения) социализации ребенка в инклюзивной группе дошкольного образовательного учреждения. Приведены результаты анкетирования среди родителей в детских образовательных организациях с определением категорий детей, нуждающихся в услугах тьютора. Сделан вывод о развитии тьюторства и его востребованности со стороны родителей и педагогов в дошкольных образовательных организациях.

Ключевые слова: тьютор, дошкольная образовательная организация, детский сад, ребенок, ограниченные возможности здоровья, инвалидность, инклюзивное образование

\title{
Tutorship in a pre-school educational organization
}

This paper examines the legislative framework for tutoring support for children with disabilities and disabilities in pre-school settings: the Federal State Educational Standard for Preschool Education, the Unified Qualification Handbook of Positions, the Order of the Ministry of Health and Social Development of the Russian Federation "On the Approval of Professional Skills Qualifications for Education Workers", Professional Tutor Standard. The foundations of the formation and development of tutor support in the context of inclusive-oriented pre-school educational organizations are defined: the formation and development of equal treatment for all students and the creation of special conditions for the educational environment. The categories of students are indicated, in respect of which tutoring support is provided. The technology of conducting the parental meeting during the period of introduction of the child into an inclusive group is disclosed. The specificity of tutoring activity is determined depending on the stage (adaptive, contact, self-determination) of the child's socialization in the inclusive group of preschool educational institutions. The results of questioning among parents in children's educational organizations are given with the definition of the categories of children who need tutor services. A conclusion is drawn on the development of tutoring and its relevance on the part of parents and educators in pre-school educational organizations.

Key words: tutor, pre-school educational organization, kindergarten, child, limited health opportunities, disability, inclusive education 
Профессиональный стандарт тьютора в рамках специальностей воспитательной направленности действует в России со 2 февраля 2017 года и регламентирует «организацию воспитательного процесса с целью духовно-нравственного, интеллектуального, физического развития и позитивной социализации обучающихся на основе формирования у них опыта социально и личностно значимой деятельности, поддержки их социальных инициатив и учета индивидуальных потребностей» [8]. Наименование базовой группы, должности (профессии) или специальности включает в перечень, наряду с другими, педагогических работников дошкольной образовательной сферы.

Вышеперечисленные документы указывают на то, что деятельность тьютора по обучению, воспитанию и развитию детей с ОВ и инвалидностью в дошкольных образовательных организациях достаточно подробно регламентируется.

Материалами данной статьи так же стали результаты анкетирования и интервьюирования, проведенного среди 197 респондентов дошкольных образовательных организаций г.о. ОреховоЗуево Московской области.

Для проведения исследования был использован комплекс методов: анализ законодательных источников и исследований по проблеме, обобщение, прогнозирование, наблюдение, анкетирование, интервьюирование родителей детей с ОВЗ и инвалидностью с целью выяснения потребности в тьюторе, обобщение передового педагогического опыта.

Результаты исследования дошколто фикационный справочник должностей [3], Приказ Минздравсоцразвития РФ «Об утверждении профессиональных квалификационных групп должностей работников образования» [7], Профессиональный стандарт тьютора [8].

Развитие тьюторской деятельности, в том числе, в дошкольных образовательных организациях, обусловлено включением в профессиональную квалификационную группу должностей педагогических работников, с начала 2010 года - в Единый квалификационный справочник должностей.

Федеральный государственный образовательный стандарт дошкольного образования (ФГОС ДО) [11], вступивший в силу 1 января 2014 года, в качестве основных задач преподносит те, которые непосредственно связаны с развитием инклюзии и тьюторского сопровождения: «обеспечение равных возможностей для полноценного развития каждого ребенка в период дошкольного детства независимо от места жительства, пола, нации, языка, социального статуса, психофизиологических и других особенностей (в том числе ограниченных возможностей здороВья); охраны и укрепления физического и психического здоровья детей, в том числе их эмоционального благополучия» [11].

Профессия «тьютор» в настоящее время активно развивается в образовательных организациях различных ступеней. Данный факт обусловлен необходимостью личностно-ориентированного сопровождения и индивидуализации образовательного процесса для детей с ограниченными возможностями здоровья и инвалидностью, констатируемой научным сообществом и членами ближайшего микросоциума ребенка. Исследования, посвященные изучению мнения о возможностях и способностях граждан, имеющих инвалидность и необходимости тьюторской деятельности, показали острую заинтересованность в тьюторе (помощнике) как самих лиц с ОВ3, так и их семей, педагогов образовательных организаций $[1 ; 2 ; 5 ; 10 ; 14]$.

С началом пенсионной реформы в РФ, многие родители, ранее не заявлявшие своего ребенка в медицинские учреждения для получения статуса инвалидности, начали делать это. Данный факт связан с сохранением пенсионного возраста для родителей, имеющих детейинвалидов. Ожидаемое при этом возрастание количества детей с ОВЗ и инвалидностью неизбежно приведет к увеличению спроса в тью- 
торской помощи и наличию рекомендаций и показаний к ней.

Тьюторское сопровождение различных категорий обучающихся в современной педагогической науке и практике является одним из инновационных личностно-ориентированных методов взаимодействия.

Изучению различных аспектов теории и практики тьюторской деятельности, подготовки педагогов, моделированию подготовки и взаимодействия тьютора с другими специалистами посвящены работы современных Российских и зарубежных педагогов и психологов: Г.В. Ганьшиной, Е.И. Кобыща, Т.М. Ковалевой, Г.В. Луниной, С.Ю. Поповой, В.П. Сергеевой, А.А. Терова, М.Ю. Чередилиной, Al Salami M.K., Burry-Stock J.A., Dorogan L., Makela C.J., de Miranda M.A., Pritchard D., Varrella G.F., Yager R.E. [2; 4-6; 12-18] и др. В последние годы появились работы, посвященные специфике тьюторского сопровождения: направлений деятельности, его особенностей и места в современной науке и практике, специфике нормативно-правового оформления, ответственности и др. [2; 4-6; 12; 19].

Несмотря на большое внимание к вопросам тьюторского сопровождения в дошкольной среде, ряд концептуальных вопросов является недостаточно разработанными. Это прикладные аспекты работы тьютора; знания, умения и навыки, которыми он должен обладать; поле профессиональных обязанностей; направления деятельности; сфера ответственности и пр.

Федеральные государственные образовательные стандарты направлены и ориентированы на современные требования, связанные с гуманизацией образовательной сферы. Социальный заказ формируется в русле готовности общества к восприятию лиц с ОВЗ и инвалидностью. В данном направлении наблюдается преимущество дошкольных образовательных организаций.

На дошкольной ступени образования работа по инклюзии осуществляется в отношении различных категорий обучающихся. Это дети с различной степенью нарушений слуха, зрения, опорно-двигательного аппарата. В отличие от школьных, средних профессиональных и высших образовательных организаций, дошкольные очень часто дают успешную подготовку детям с нарушениями интеллекта, общения. Находясь в комфортных условиях дошкольной группы, успешно социализируются в дошкольной среде дети, имеющие сложные для обучения в школе диагнозы - ранний детский аутизм, задержка психического развития, умственная отсталость.

Более комфортным, чем в школьной среде, является общение детей с нормальным развитием и ребенка с его нарушением. Воспринимая в младшем возрасте ребенка с ОВЗ или инвалидностью как данность, в старших группах детского сада отношение существенно не меняется, лишь переосмысливается. Дети с наибольшей эффек- тивностью принимают особенности ребенка, в естественных условиях пытаются помочь ему.

Проще строится работа с родителями инклюзивной группы детей, которые более лояльны к детям с инвалидностью и ОВЗ младшего возраста. Это связано с поздней постановкой диагноза ребенку, отсутствием явных проявлений заболевания в раннем и младшем дошкольном возрасте, терпимостью со стороны взрослых к «чудачествам», «капризам» и «особенностям» маленького человека. Опросы педагогических работников дошкольных образовательных организаций показали, что в среднем для адаптации родителей к «особому» ребенку с явными и заметными физическими нарушениями требуется 2-3 недели.

\section{Обсуждение результатов}

Обсуждение результатов исследования состоялось на III Всероссийской научно-практической конференции с международным участием «Инклюзивное образование: теория и практика», прошедшей 15 июня 2018 г в г. Орехово-Зуево Московской области. Участники конференции в совместной беседе с директором Федерального бюджетного научного учреждения «Институт изучения детства, семьи и воспитания Российской академии образования» Т.В. Волосовец, среди основных проблем дошкольного образования выявили проблему развития тьюторской поддержки.

Основой тьюторского сопровождения в условиях инклюзивно ориентированных дошкольных образовательных организаций является идея формирования и развития равного отношения ко всем обучающимся. В отдельных случаях для адаптации ребенка требуется создание специальных условий образовательной среды. Для этого в группах устанавливаются адаптирующие средства для осуществления режимных моментов, специальное оборудование для работы на занятиях. При других нарушениях специальное оборудование (аудиовизуальные средства, специальные рабочие места, оборудованные туалетные комнаты и пр.) не требуются. Так, для детей с ранним детским аутизмом (РДА) или легкой степенью умственной отсталости (УО) Психологомедико-педагогическая комиссия рекомендует сопровождение тьютора.

В соответствии с действующим законодательством, тьютором в детском саду может работать специалист со средним или высшим педагогическим образованием. В современных условиях им может быть воспитатель, помощник воспитателя с педагогическим образованием.

Содержание педагогической деятельности тьютора в дошкольной образовательной организации вызывает множество вопросов и споров среди ученых и практических работников. В современной научной литературе выделяется три 
основных периода социализации «особого» ребенка в дошкольной среде: адаптации, налаживания контактов, самоопределения.

Особо следует отметить, что при введении в инклюзивную группу «особого» ребенка, обязательно следует провести подготовительный этап. На данном этапе тьютору необходимо самому познакомиться с ребенком, изучить медицинскую карту и характеристики, пообщаться с родителями (законными представителями), другими членами семьи, изучить особенности взаимодействия с ребенком у специалистов, работающих с ним (медицинских работников, реабилитологов, дефектологов и пр.).

В подготовительный период педагогическому коллективу при явно выраженном нарушении у ребенка нужно подготовить к его восприятию родителей инклюзивной группы детского сада. Совместно с представителем администрации дошкольной образовательной организации (заведующим, его заместителем), воспитателями, психологом, логопедом, привлеченными специалистами медицинского профиля (при необходимости), проводится родительское собрание. Обычно собрание строится по классической технологии с привлечением специфических моментов. Практический опыт работы в инклюзивной образовательной среде показал эффективность проведения собрания для родителей в следующей последовательности.

1. Выступает представитель администрации или психолог с докладом о пользе инклюзивного образования для всех детей группы. В доклад можно включить и наглядно проиллюстрировать данные исследований, демонстрирующих развитие личностных качеств здоровых детей при инклюзивном обучении.

2. Представитель администрации или один из воспитателей объявляет о мотивированном решении принятия в группу ребенка с особенностями в развитии.

3. Выступает родитель (законный представитель) ребенка с рассказом о малыше: его рождении, лечении, особенностях развития и достижениях на настоящий момент. Рассказ целесообразно сопроводить презентацией фото, видео, поделок ребенка и пр. Это наиболее эмоциональная часть родительского собрания, когда родители ребенка с нормальным развитием понимают, что не все дети развиваются одинаково, задают вопросы, учатся сопереживать.

4. Тьютор, психолог, логопед, при необходимости - привлеченный специалист медицинского профиля рассказывают об особенностях взаимодействия с ребенком и рисках, связанных с заболеванием.

5. Психолог рассказывает родителям, с помощью каких методов и приемов рассказать своему ребенку о новом члене детского коллектива и его особенностях.
6. Предлагается выступить родителям, высказать свое мнение. Многолетний педагогический опыт показывает, что на данном этапе проведения собрания или через некоторое время, когда приходит осмысление, находятся родители, не желающие, чтобы их ребенок получал образование вместе с «инвалидом». В этом случае семье ребенка должна быть предложена альтернатива по переводу их ребенка в параллельную группу.

7. В заключение собрания воспитатель подводит итоги, благодарит всех собравшихся.

Анализируя взаимоотношения в коллективе инклюзивной группы детей и их родителей, опытные воспитатели дошкольных образовательных организаций г.о. Орехово-Зуево Московской области, Орла, Омска, отмечают высокий уровень сплоченности, быстрое решение возникающих проблем, более тесное общение в свободное от посещения детского сада время в коллективах, которых присутствуют дети с ограниченными возможностями здоровья или инвалидностью. Этот факт обусловлен правильной работой педагогического коллектива на подготовительном этапе.

Переходя к тьюторской деятельности, осуществляющейся непосредственно с ребенком, следует вычленить и определить ее специфику на каждом этапе социализации: адаптационном, контактном, самоопределения.

В период адаптации ребенка с ОВЗ или инвалидностью и вовлечения его в образовательную среду дошкольного учреждения, тьютор требуется для создания комфортных для ребенка условий в процессе ухода из-под родительской опеки и первичном знакомстве с группой, воспитателями, детьми. Функции тьютора состоят в оказании помощи родителям в оставлении ребенка в группе; оказании помощи воспитателям в вызове интереса к новому окружению: обстановке группы, детям, новым формам занятий, сосредоточении его на новых игрушках. На данном этапе тьютор знакомит с индивидуальными средствами и приспособлениями: шкафчиком, стульчиком, местом за столом, спальным местом, полотенцем, зубной щеткой и пр., объясняет правила и способы эффективного пользования ими в зависимости от возможностей ребенка.

Следом за адаптационным наступает период налаживания контактов. На данном этапе тьютор способствует организации успешного общения ребенка с ОВЗ или инвалидностью с детьми, педагогами (воспитателями, музыкальным руководителем, преподавателем по физической культуре, преподавателем по иностранному языку, приходящими руководителями кружковых занятий, логопедом и пр.), помощником воспитателя; родителями детей инклюзивной группы. После знакомства с кругом непосредственного общения, для общего развития ребенка целесообразно познакомить с особенностями работы кухни, прачечной, медицинского кабинета. Результатом 
взаимоотношений в данный период должны быть стойкие и эффективно работающие связи между ребенком с ОВЗ или инвалидностью и педагогами, специалистами, детьми, их родителями, обслуживающим персоналом и пр. На данном этапе тьютору нужно уделять большое значение обучению окружающих правильной, своевременной и тактичной помощи «особому» ребенку.

Многолетний собственный педагогический опыт и обсуждение с коллегами показали, что в данный период важно настроить сердобольный персонал дошкольной образовательной организации на то, чтобы они воспринимали ребенка с ОВ3 как личность и не баловали его своим вниманием. С ребенком с ограниченными возможностями здоровья или инвалидностью следует общаться, максимально стараясь предъявлять ему те же требования, как и к детям с нормальным развитием.

Важным на данном этапе является обучение детей простейшим навыкам помощи «особому» ребенку. Спросить, нужно ли помочь, подать полотенце, поправить рубашку, подвинуть стульчик и пр. При правильно проведенном периоде налаживания контактов и ненавязчивом акцентировании внимания на проблемах, к старшим группам детского сада у ребенка появляются друзья, сопровождающие его во время режимных моментов, готовые прийти на помощь во время неудачи. Сам ребенок с ОВЗ учится эффективно взаимодействовать с окружающими, тактично просить о помощи, не обижаться, понимать различную реакцию.

Конечным периодом социализации ребенка с ограниченными возможностями в микросоциуме детского коллектива является период самоопределения. Его результатом должно быть осознание собственных предпочтений, желаний, не противоречащих общим правилам и задачам функционирования дошкольной образовательной организации. Роль тьютора на данном этапе заключается не только в организации стойкого контактирования с детьми и взрослыми, но и в приучении ребенка к правильному, вежливому и тактичному выражению своей просьбы в различной среде.
Совместно с другими членами коллектива тьютор способствует созданию специальных педагогических условий для успешного вхождения всех обучающихся инклюзивной группы дошкольной образовательной организации в образовательный процесс и их адекватного самоопределения в микросоциуме.

В существующем законодательстве тьютор предусмотрен только для сопровождения детей с ОВ3 и инвалидностью. В этой связи хочется отметить, что данная услуга востребована и для других детей детского дошкольного учреждения.

Проведенное анкетирование в ДОО организациях г.о. Орехово-Зуево 216 родителей показало, что в услугах тьютора нуждаются следующие категории детей:

- дети младшего возраста, впервые посещающие дошкольное учреждение;

- трудно адаптирующиеся к условиям массовой группы;

- часто болеющие дети;

- дети мигрантов, беженцев и вынужденных переселенцев;

- двуязычные дети;

- дети этнических меньшинств (цыганская диаспора и пр.).

В 2018-2019 учебном году в детские сады Московской области планируется принять тьюторов для сопровождения детей с ОВЗ и инвалидностью.

Заключение

Таким образом, тьюторская деятельность в дошкольных образовательных организациях широко востребована и имеет большие перспективы. В настоящее время данная форма сопровождения только начинает развиваться. Рассмотрение некоторых аспектов тьюторской поддержки, представленное в данном исследовании, не разрешает всего многообразия проблем. Требуется разработка прикладных аспектов работы тьютора; конкретизация его профессиональных обязанностей и пр.

ЛИТЕРАТУРА

1. Анищева Л. И., Ащеулов Ю. Б., Остапенко Р. И. Изучение мнения населения Воронежской области о возможностях и способностях граждан, имеющих инвалидность [Электронный ресурс] // Перспективы науки и образования. 2017. № 6. URL: http://pnojournal.wordpress.com/archive (дата обращения: 07.05.2018).

2. Ганьшина Г.В., Лунина Г.В. Тьюторское сопровождение адаптации детей к условиям дошкольной образовательной организации // Современные проблемы науки и образования. 2017. № 4. С. 165.

3. Единый квалификационный справочник должностей руководителей, специалистов и служащих (приказ № 761-н Миздравсоцразвития от 26.08.2010, зарегистрирован в Минюсте РФ 6 октября 2010 г. № 18638) [Электронный ресурc] URL: http://www.consultant.ru/cons/cgi/online.cgi?req=doc\&base=LAW\&n=116278\&rnd $=290511.74069522 \& d s t=100077 \& f l d=134 \# 0$. (дата обращения: 17.06.2018).

4. Ковалева Т. М., Кобыща Е. И., Попова (Смолик) С. Ю., Теров А. А., Чередилина М. Ю. Профессия «тьютор». М.: Тверь: «СФК-офис», 2012. 246 с.

5. Медведева Е.Ю., Новикова Н.Н. Оценка уровня сформированности пространственных представлений 
старших дошкольников с нормой речевого развития и с общим недоразвитием речи [Электронный ресурс] // Перспективы науки и образования. 2018. № 2. URL: http://pnojournal.wordpress.com/archive 4 (дата обращения: 27.05.2017).

6. Сутковая Н.В., Молчанов С.Г. Тьюторские функции педагога в пространстве реализации индивидуальной образовательной программы в дошкольном образовании // Современная высшая школа: инновационный аспект. 2016. Т. 8. № 2 (32). С. 163-179.

7. Приказ Минздравсоцразвития РФ от 5 мая 2008 г. № 216-н «Об утверждении профессиональных квалификационных групп должностей работников образования» [Электронный ресурc] URL: http:// www.consultant.ru/cons/cgi/online.cgi req $=$ doc \&base $=$ LAW $\& n=125537 \& \mathrm{fld}=134 \& \mathrm{dst}=1000000001,0 \& \mathrm{r}$ $\mathrm{nd}=0.12264931605617102 \# 0$ (дата обращения: 12.06.2018).

8. Приказ Министерства труда и социальной защиты РФ от 10 января 2017 г. № 10 н «Об утверждении профессионального стандарта «Специалист в области воспитания». [Электронный ресуpc] URL: http://www. garant.ru/products/ipo/prime/doc/71495630/ (дата обращения: 17.05.2018).

9. Тимохина, Т.В. Нормативно-правовые аспекты инновационной тьюторской деятельности [Текст] / Т.В. Тимохина // Право и образование. 2017. № 11. С. 32-36.

10. Тимохина Т.В. Тьюторство в сопровождении обучаемого // Инклюзивная образовательная среда и ее развитие Международная конференция: круглый стол с участием молодых исследователей. Российский государственный социальный университет / Под ред. Л.В. Мардахаева. Москва, 2018. С. 18-22.

11. Федеральный государственный образовательный стандарт дошкольного образования [Электронный ресурc]. URL: http://www.firo.ru/?page_id=11003 (дата обращения: 08.05.2018).

12. Тьютор в образовательном пространстве: учебное пособие /В.П. Сергеева [и др.]. М.: УЦ Перспектива, 2014. 216 c.

13. Al Salami M.K., Makela C.J., de Miranda M.A. Assessing Changes in Teachers' Attitudes toWard Interdisciplinary Stem Teaching International Journal of Technology and Design Education. 2017. T. 27. № 1. C. 63-88.

14. Bogdanov D. Personality, Style and Authority on Tutor in the Institution «Home» // Научни трудове на Съюза на учените Пловдив. Серия А: Обществени науки, изкуство и култура. 2016. Т. 2. С. 74-79.

15. Burry-Stock J.A., Dorogan L., Varrella G.F., Yager R.E. Russian/US comparison using the expert science teaching educational evaluation model (esteem) // International Journal of Science Education. 2000. T. 22. № 4. Pp. 419-433.

16. Heath J. Methodological individualism // The Stanford Encyclopedia of Philosophy Archive. Spring 2015 Edition. URL: http://plato.stanford.edu/archives/spr2015/entries/methodological-individualism (дата обращения 22.05.2018)

17. MacSwan J. A multilingual Perspective on Translanguaging // American Educational Research Journal. 2017. T. 54. № 1. C. 167-201.

18. Pritchard D. Epistemic virtue and the epistemology of education // Journal of Philosophy of Education. 2013. No 47 (2). Pp. 236-247. DOI: http://10.1111/1467-9752.12022

19. Tatiana V. Timohina, Olga G. Pavlova, Nadezhda M. Pugacheva. Model of tutor support for disabled persons and persons with special educational needs in the conditions of inclusive education of the Moscow region // Advances in Computer Science Research (ACSR), volume 72 (ITSMSSM 2017) 344 IV International Research Conference «Information Technologies in Science, Management, Social Sphere and Medicine» Part of series Advances in Computer Science Research. Publication date: December 2017. Pp. 345-347.

REFERENCES

1. Anischeva L.I., Ashcheulov Yu.B., Ostapenko R.I. Study of the opinion of the population of the Voronezh region about the capabilities and abilities of citizens with disabilities. Perspektivy nauki i obrazovania - Perspectives of science and education. 2017. № 6. Available at: http://pnojournal.wordpress.com/archive (accessed 7 May 2018). (in Russian)

2. Ganshina G.V., Lunina G.V. Tutor support adaptation of children to the conditions of pre-school educational organization. Modern problems of science and education. 2017. No. 4. P. 165. (in Russian)

3. Unified Qualification Directory of Managers, Specialists, and Employees (Order No. 761-n Mizdravsotsrazvitiya of August 26, 2010, registered in the Ministry of Justice of the Russian Federation on October 6, 2010 No. 18638) [Electronic resource]. Available at: http://www.consultant.ru/cons /cgi/online.cgi?req=doc\&base $=$ LAW \&n=11627 $8 \& \mathrm{rnd}=290511.74069522 \& \mathrm{dst}=100077 \& \mathrm{fld}=134 \# 0$. (accessed 17 June 2018). (in Russian)

4. Kovaleva TM, Kobyschina E.I., Popova (Smolik) S.Yu., Terov A.A., Cheredilina M.Yu. Profession "Tutor". Moscow, Tver: SFK-office Publ., 2012. 246 p. (in Russian)

5. Medvedeva E.Yu., Novikova N.N. Assessment of the level of formation of spatial representations of senior preschoolers with the norm of speech development and with a general underdevelopment of speech [Electronic resource]. Perspektivy nauki i obrazovania - Perspectives of science and education. 2018. no. 2. Available at: http:// pnojournal.wordpress.com/archive 4 (accessed 27 May 2018). (in Russian)

6. Sutkovaya N.V., Molchanov S.G. Tutor functions of a teacher in the space of the implementation of an individual educational program in preschool education. Modern Higher School: an innovative aspect. 2016. Vol. 8. no. 2 (32). pp. 163-179. (in Russian)

7. Order of the Ministry of Healthcare of the Russian Federation dated May 5, 2008 No. 216-n "On the approval of professional qualification groups of educational positions" [Electronic resource]. Available at: http://www. consultant.ru/cons/cgi/online.cgi?req=doc\&base $=$ LAW \& $n=125537 \&$ fld $=134 \&$ dst $=1000000001.0 \& \mathrm{rnd}=$ 0.12264931605617102 \# 0 (accessed 12 June 2018). (in Russian)

8. Order of the Ministry of Labor and Social Protection of the Russian Federation dated January 10, 2017 No. 10n 
"On approval of the professional standard" Specialist in the field of education ". [Electronic resource]. Available at: http://www.garant.ru/products/ipo/prime/doc/71495630/ (accessed 17 May 2018). (in Russian)

9. Timokhina T.V. Regulatory aspects of innovative tutoring activities. Law and Education. 2017. no. 11. P. 32-36. (in Russian)

10. Timokhina T.V. Tutoring accompanied by a student // Inclusive educational environment and its development International Conference: round table with the participation of young researchers. Russian State Social University / Ed. L.V. Mardahaev. Moscow, 2018. p. 18-22. (in Russian)

11. Federal State Educational Standard for Preschool Education [Electronic resource]. Available at: http://www.firo. ru/?page_id=11003 (accessed 8 May 2018). (in Russian)

12. Tutor in the educational space: textbook / W.P. Sergeeva [et al.]. Moscow, TC Perspektiva Publ., 2014.216 p. (in Russian)

13. Al Salami M.K., Makela C.J., de Miranda M.A. Assessing Changes in Teachers' Attitudes toWard Interdisciplinary Stem Teaching. International Journal of Technology and Design Education. 2017. V. 27. no. 1. pp. 63-88.

14. Bogdanov D. Personality, Style and Authority on the Tutor in the Institution «Home» // Scientific papers of the Union of Scientists in Plovdiv. Series A: Social Sciences, Art and Culture. 2016. V. 2. pp. 74-79.

15. Burry-Stock J.A., Dorogan L., Varrella G.F., Yager R.E. Russian/US comparison using the expert science teaching educational evaluation model (esteem). International Journal of Science Education. 2000. V. 22. no. 4. pp. 419-433.

16. Heath J. Methodological individualism // The Stanford Encyclopedia of Philosophy Archive. Spring 2015 Edition. Available at: http://plato.stanford.edu/archives/spr2015/entries/methodological-individualism (accessed 22 May 2018)

17. MacSwan J. A multilingual Perspective on Translanguaging. American Educational Research Journal. 2017. V. 54. no. 1. pp. 167-201.

18. Pritchard D. Epistemic virtue and the epistemology of education. Journal of Philosophy of Education. 2013. no. 47 (2). pp. 236-247. DOI: http://10.1111/1467-9752.12022

19. Tatiana V. Timohina, Olga G. Pavlova, Nadezhda M. Pugacheva. Model of tutor support for disabled persons and persons with special educational needs in the conditions of inclusive education of the Moscow region // Advances in Computer Science Research (ACSR), volume 72 (ITSMSSM 2017) 344 IV International Research Conference «Information Technologies in Science, Management, Social Sphere and Medicine» Part of series Advances in Computer Science Research. Publication date: December 2017. pp. 345-347.

Информация об авторе
Тимохина Татьяна Васильевна
(Россия, Московская область, г. Орехово-Зуево)
Кандидат педагогических наук
Доцент кафедры педагогики
гоу во МО «Государственный гуманитарно-
технологический университет»
E-mail: timohina.tv@mail.ru

Ссылка для цитированиягост

Тимохина Т. В. Тьюторство в дошкольной образовательной организации // Перспективы науки и образования. 2018. № 5 (35). С. 103-109. doi: 10.32744/pse.2018.5.11

\section{Information about the author} Tatyana V. Timokhina

(Russia, Moscow region, Orekhovo-Zuyevo) $\mathrm{PhD}$ in Pedagogical Sciences

Associate Professor of the Department of Pedagogy

State Humanitarian and Technological University E-mail: timohina.tv@mail.ru
For Reference ${ }^{\text {APA }}$

Timohina, T. V. (2018). Tutoring in pre-school education establishment. Perspektivy nauki i obrazovania Perspectives of Science and Education, 35 (5), 103-109. doi: 10.32744/pse.2018.5.11. (In Russ., abstr. in Engl.) 